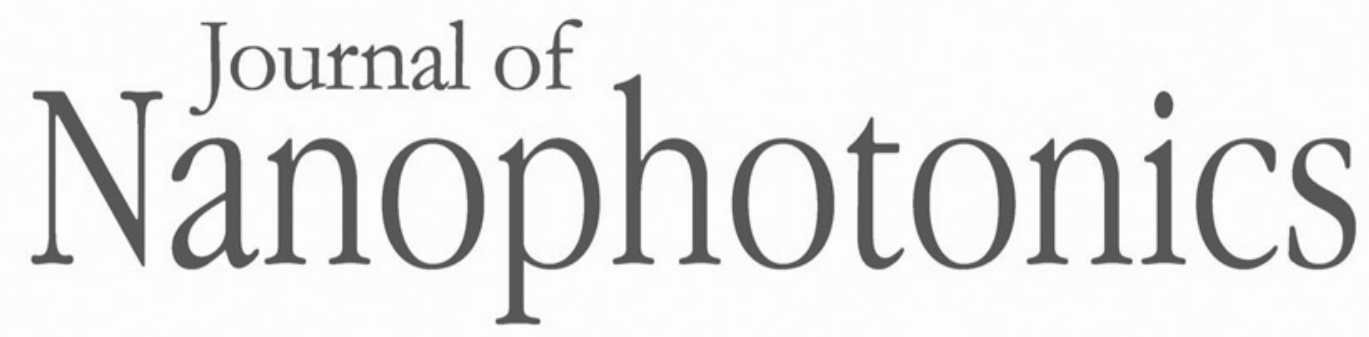

Nanophotonics.SPIEDigitalLibrary.org

\title{
Special Section Guest Editorial: Nanoplasmonics
}

Richard Soref

Justin Cleary

Sasan Fathpour

\section{SPIE.}




\title{
Special Section Guest Editorial: Nanoplasmonics
}

\author{
Richard Soref, ${ }^{\mathrm{a}, *}$ Justin Cleary, ${ }^{\mathrm{b}, *}$ and Sasan Fathpour ${ }^{\mathrm{c}, *}$ \\ ${ }^{a}$ The Engineering Program, University of Massachusetts at Boston, Boston, \\ Massachusetts 02125-3393, United States \\ ${ }^{\mathrm{b}}$ Air Force Research Laboratory, Sensors Directorate, Wright-Patterson AFB, \\ Ohio 45433-7320, United States \\ ${ }^{\mathrm{c}}$ CREOL, The College of Optics and Photonics, University of Central Florida, Orlando, \\ Florida 32816-2700, United States
}

\begin{abstract}
Nanoplasmonics is an emerging electromagnetic-wave technology that exploits deep-subwavelength nanoscale composites of conductors and dielectric-semiconductors for new free-space and on-chip waveguided applications. The nanoplasmonic possibilities include surface waves, bulk waves, metasurfaces, and quantum confinement utilized at wavelengths in the visible, infrared, and terahertz regions, with the longer wavelengths leading to lower propagation loss. Nanoplasmonics complements nanophotonics, and the two technologies can be cointegrated on a chip for new functionality and synergism. The eleven papers in this special section present a snapshot of current international research in this field. Invited papers cover group-IV mid-infrared plasmonics, tunable plasmonic materials for optical modulation, and beamsteering and plasmonic resonance within a photonic-crystal nanobeam. An invited review article gives an overview of midinfrared plasmonic materials. The contributed papers explore passive and active plasmonic devices (e.g., modulators, waveguides, resonators, spectral filters, lenses, and nanoantennas), and the plasmonic properties of nanostructures, such as nanoparticles, nanorods, and nanoshells. The guest editors thank all authors who have contributed to this special section and hope that the readers will enjoy the selection.
\end{abstract}

\footnotetext{
*Address all correspondence to: Richard Soref, E-mail: soref@ rcn.com; Justin Cleary, E-mail: justin.cleary.1@us.af.mil; Sasan Fathpour, E-mail: fathpour@creol.ucf.edu

(1) 2015 Society of Photo-Optical Instrumentation Engineers (SPIE)
} 